\title{
Effects of Large-Scale Wind Integration on China Northwest Regional Power System and Future Solutions
}

\author{
Xingzhong Bai*. Jianxue Wang.**. Xiaozhong Wan*. Mingqiao Peng*. Xiaoqi Zhang*. Jian Geng*** \\ *Northwest Grid of China Company, Xi'an, 710048 \\ CHINA (Tel: 86-29-8750 6620; e-mail: baixz@nw.sgcc.com.cn). \\ **Xi'an Jiaotong University, Xi'an, 710049 CHINA (e-mail: \\ jxwang@mail.xjtu.edu.cn) \\ *** State Grid Electric Power Research Institute, \\ Nanjing, China (e-mail: gengjian@sgepri.sgcc.com.cn).
}

\begin{abstract}
The paper introduces the current planning integration situation of the wind power in Northwest Grid of China. The large-scale wind power integration, characterized by concentrated and high voltage level interconnection, makes appreciable effects on power system in stability control, frequency control, load tracking and voltage control. In this situation, the paper studies new requirements of power generation scheduling, dispatch, operation management, power market modelling, grid-connecting operation management, ancillary service management and so on. Finally, the paper introduces the solutions and strategies such as to strengthen the $750 \mathrm{kV}$ grid construction, increase power export of the region, develop a Wind EMS, improve wind power forecasting, explore combined dispatching of wind power and other power plants, and introduce new power market mechanisms.
\end{abstract}

Keywords: power network; wind power; integration; scheduling;

\section{INTRODUCTION}

In recent years, global energy security and environmental protection issues have become increasingly prominent. Since the wind power technology has good maturity, with conditions of large-scale development and the prospects for commercial development, it has been rapidly developed. According to the planning, during the period of the 12th Five-Year Development Program of China, some large-scale wind farms will be integrated into the Northwest grid of China, and this will bring new challenges to the security management and economic operation of electric network. It is of great importance to deeply study the influence on operation security and scheduling management of Northwest Grid with large-scale wind power integration. To guarantee the safety and stability of operation after the integration of wind power, it is necessary to make reasonable coping strategies and preventive measures.

\section{STATUS AND PLANNING OF NORTHWEST WIND POWER}

The northwest area of China is rich in wind energy resources. According to the statistic data, the amount of wind energy resources of northwest China is as high as 300,000MW, accounting for $1 / 3$ of the country's total land-based wind energy resources. Wind energy resources in the northwest China mainly distribute in northern Hexi Corridor, Gansu, Ningxia Helan Mountain, Liupan Mountain, Dabancheng, Shisanjianfang and other areas The geographical distribution of wind power is shown in fig.1. Meanwhile, the developing conditions are good, with the capability of establishing a wind power base of 10,000MW.

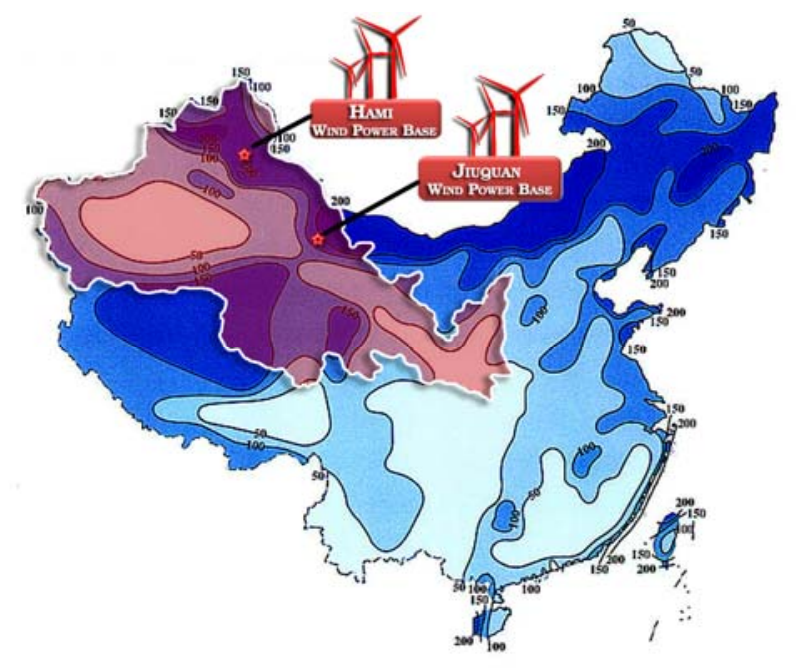

Fig.1 The distribution of wind power

With the support of a series of green energy policies, the overall wind power market in northwest China is effectively promoted. During the 11th Five-Year Development Program period, the wind power development of the Northwest Grid has been accelerated. In Gansu, 10 wind farms in Anxi, Yumen, Jingtai and other areas are developed. In Ningxia, 8 wind farms in Helan Mountain area are developed. In Xinjiang, wind farms in Dabancheng, Alashankou, Shisanjianfang and other areas are developed. 
In accordance with the plan, it is expected that the total installed capacity of wind power in northwest China will reach $9790 \mathrm{MW}$ to the end of 2010. The wind power amount in Gansu will be $5160 \mathrm{MW}$, in Ningxia 1030MW, in Xinjiang $3000 \mathrm{MW}$, in Alashan Monning and Inner Mongolia border 600 MW. By then, the installed capacity of wind power in northwest China will account for about $11 \%$ of the total installed capacity of Northwest Grid of China (NWGC). This amount also accounts for about $25 \%$ of the estimated maximum load in NWGC. By 2020, it is expected that the total installed capacity of wind power in NWGC will reach about $30,000 \mathrm{MW}$, and in the future it will be more than 40,000MW.

\section{CHARACTERISTICS OF WIND POWER DEVELOPMENT IN NORTHWEST CHINA}

\subsection{Concentrated Integration into Power Grid}

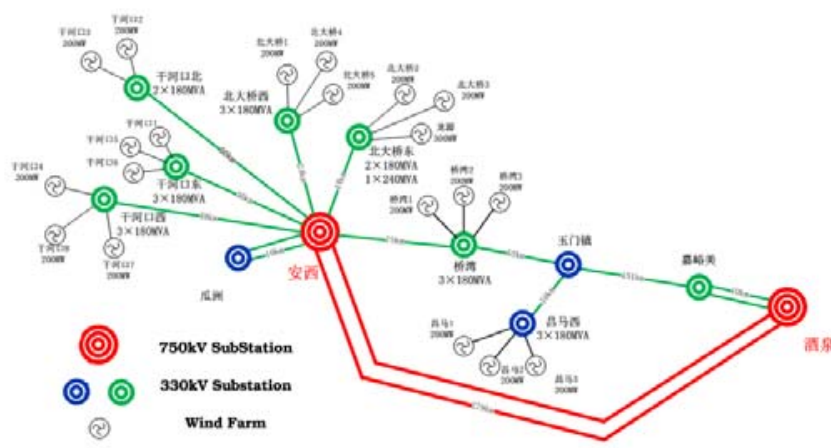

Fig.2 Wind farm system diagram

Wind resources in northwest China mainly distribute in Gansu and Xinjiang. For example, in Gansu, the total amount of available wind energy reserve ranges from 19500 to 20000 MW, most of which concentrates in the bottom region of west boundary of Hexi Corridor, from Jiayuguan to the western border of Anxi. In the south of this area there is the Qilian pulse. In the north there are Kitayama mountains, presented by Mazong mountain. In the middle there is a flat desert. Thus, a valley between two mountains forms a favorable terrain, resulting in rich wind resources. In Jiuquan wind power base, $5160 \mathrm{MW}$ wind power developed in onestage mainly integrates into the power system through seven $330 \mathrm{kV}$ substations, sending out through two $750 \mathrm{kV}$ substations. However, this concentrated way of integration causes many problems to operation. The wind farm system diagram is shown in fig. 2 .

\subsection{Far from Load Centers}

The load centers of the NWGC are mainly in the middle and east area. The main load centers are Guanzhong region in Shanxi, Lanzhou, Baiyin regions in Gansu. The nearest load center around Jiuquan wind power base is about $800 \mathrm{~km}$ away. Therefore, wind power must transmit a long distance to the load center. The geographical distribution of load and wind power is shown in fig.3.

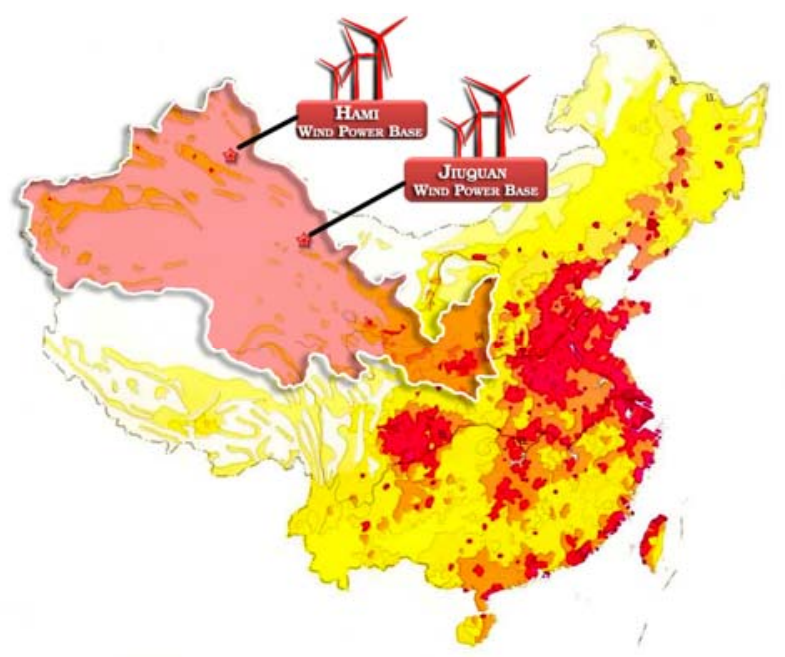

Fig.3 The distribution of load and wind power

\subsection{Located in the End of Power Grid}

Jiuquan is located in the end of Hexi Corridor, with sparse population. The regional capacity is limited, and the power network is weak. At present, this area is connected to the main $330 \mathrm{kV}$ network only by two long lines, and the stability problem of this weak network is very prominent. Despite adopting some stable measures, such as cutting units and splitting substations, wind power is still seriously hindered.

\subsection{High Voltage of Access Point}

Since the large-scale wind power in NWGC are required to be concentrated and long-distance transmitted, the voltage level of wind power integration is relatively high. Most wind farms in Jiuquan wind power base are directly integrated through $330 \mathrm{kV}$ step-up stations to $750 \mathrm{kV}$ power grid. It is the first case in the international area. Then, there are inevitably some difficulties in the voltage control.

\subsection{Poor Coordination of Wind Turbines}

In Jiuquan wind power base there are mainly two types of wind turbines, double-fed variable speed wind turbines and permanent magnet direct drive wind turbines. Double-fed and direct drive units have the capability of active and reactive power regulation, low voltage ride through and other functions. However, due to various reasons, the domestic wind turbines do not have these basic functions. Overall, the standards of wind turbines in NWGC are not uniform, and these wind turbines are quite different in technique and performance. Consequently, the regulation performance of wind turbines can not satisfy the power requirements. The coordination level of wind turbines need to be increased. 


\section{PROBLEMS DURING DEVELOPMENT OF WIND POWER}

\subsection{Wind Power Does Not Match Conventional Power Supply Planning}

Match of wind Power is a problem, which is mentioned by Hannele Holttinen et al. (2003). Thermal power units in NWGC account for $69 \%$ of total installed capacity, and in winter there are more cogeneration units. Hydropower units, as a rapid adjustment to system power, account for only $27 \%$ of total installed capacity. And the peak shaving capacity is limited by the constraint of valley comprehensive utilization. Moreover, the civil load in NWGC accounts for a high proportion, and the gap between load peak and valley is very high. Thus, if large-scale wind power integrates, the existing proportion of hydropower units and gas generator units can not match the capacity of wind power.

\subsection{Integration of Large-scale Wind Power Leads to More Difficulties of Operation}

On the one hand, as what is introduced by Chai Chompooinwai et al. (2003), and G. Slootweg and W. L. Kling (2003), integration of large-scale wind power causes the level of frequency stability decreases. Since the scale of NWGC is relatively small, if the proportion of wind power is too high, wind power will replace part of synchronous generators. But fans generally do not produce frequency response on the system. Therefore, it will have some impact on the frequency stability. In addition, most of current wind turbines do not have the ability of low voltage ride through, if large amount of wind turbines split from the grid, it will lead to great vibration to the system frequency.

On the other hand, integration of large-scale wind power has a great deal of influence on the voltage and reactive power characteristics, which is introduced in papers by Le Thu $\mathrm{Ha}$ and Tapan Kumar Saja (2004), and MP Palsson (2002). In Jiuquan wind power base, after large-scale wind power gets running, output changes of wind power will cause huge voltage fluctuation in large-scale and multi-voltage substations in the NWGC, especially for $750 \mathrm{kV}$ substations in Hexi. In Qinghai, since the hydropower is used to shave peak after integration of wind power, the voltage fluctuation in $750 \mathrm{kV}$ substations is obvious too. Therefore, there are many difficulties in the voltage regulation in normal operation of NWGC.

Additionally, integration of large-scale wind power affects the system power balance and the current distribution, as mentioned by Vladislav A (2003), and Mendonca, A (2005). In the accident, the automatic cut-in or cut-out of fans could lead to rapid fluctuations of system frequency, and thus the system is seriously in the risk of extended power outages.

\subsection{Inadequate Technical Support of Wind Power Dispatching Techniques}

Currently, only part real-time information of a few wind farms is transmitted to the EMS system. In many wind farms, the wind measure tower has not been installed, and many real-time data have no access to the EMS system, including wind speed, active power, reactive power, unit operations and power projections. As mentioned in papers by Dresden J and Belmans R (2006), Niknam T et al. (2008), Wiik J et al. (2002), and Chun-Lung Chen (2008), due to lack of effective technical means to support, some control methods such as peak shaving, frequency and voltage regulation, and real-time planning can not keep up with the development of wind power. Furthermore, wind power output is not included in AGC and AVC closed-loop system. Therefore, the system can not realize real-time control well, and the control is inefficient with low precision.

\subsection{Techniques of Wind Power Forecast Need to Be Improved}

Introduced in papers by D. A. Bechrakis, J. P. Deane and E. J McKeogh (2004) and Landberg et al. (2003), wind power forecast is effective to achieve optimal operation of wind power. In recent years, the Northwest China Grid Company speeds up study on wind power forecast techniques. Though the techniques are rapidly developed, the overall forecast level is not high enough to meet the dispatching applications. The ultra short-term wind power forecast ( $0-4$ hours) has not satisfactory precision, and has not been used in real-time dispatching. For the long-term wind power forecast, which is important for making plans and arrangements, the corresponding research has not been carried out yet.

\section{SOLUTIONS AND MEASURES}

\subsection{Strengthen the Construction of Wind Power Standard System}

At present, wind power in China is developing rapidly, but related technical standards are not perfect, and wind power is in urgent need of establishing technical standards. According to practical operation of wind power in northwest China, Northwest China Grid Company has made some standards, such as "Details Rules of Wind Farm Integration Technical Regulation", "Regulations of Wind Farm Integration Testing" and so on. These regulations have great significance to standard wind power integration. Northwest Grid will continue to strengthen the construction of wind power standard system, especially to: (1) make regulations about integration capability assessment of wind power; (2) construct operation indicator system (calculation of electric quantity of abandoned wind, e.g.); (3) determine the tie-line control mode of wind power inter-province consumption; (4) standardize the management of wind farm compensation and data acquisition technology; (5) standardize the integration and operation of wind power. 


\subsection{Divide Dispatching Jurisdiction Rationally}

The division of dispatching jurisdiction is the fundamental premise of specifying the duty of every dispatching institution. NWGC has specified hierarchical dispatching and jurisdiction division of wind power, wich considers the voltage level of wind power integration, wind farm/cluster capacity, wind power consumption mode and control workload, etc. In principle, wind farms are directly integrated into $330 \mathrm{kV}$ and higher voltage level power grid. The wind farm which is not directly integrated into regional power grid is allocated by local dispatching institution. The wind farm which reaches a certain scale (more than 600MW) is allocated by Northwest China Grid Dispatching Centre.

\subsection{Build the Technical Support System of Wind Power Dispatching and Improve the Wind Power Forecast System}

Large-scale integration of wind power has great influence on power grid operation. Compared with conventional energy, wind power dispatching operation has higher requirements for accuracy, rapidity, and automation. Constructing a technical support system of dispatching is important to ensure safe and stable operation of power grid and effective utilization of wind power. NWGC is speeding up construction of a set of reasonably designed, advanced and convenient wind power technical support system. It can satisfy the requirements of safe dispatching of wind power and full use of renewable energy. It can also improve the utilization efficiency of wind power and can decrease the operation cost. Flow diagram and DFD(Data flow diagram) of WindEMS are shown in Fig 4 and 5.

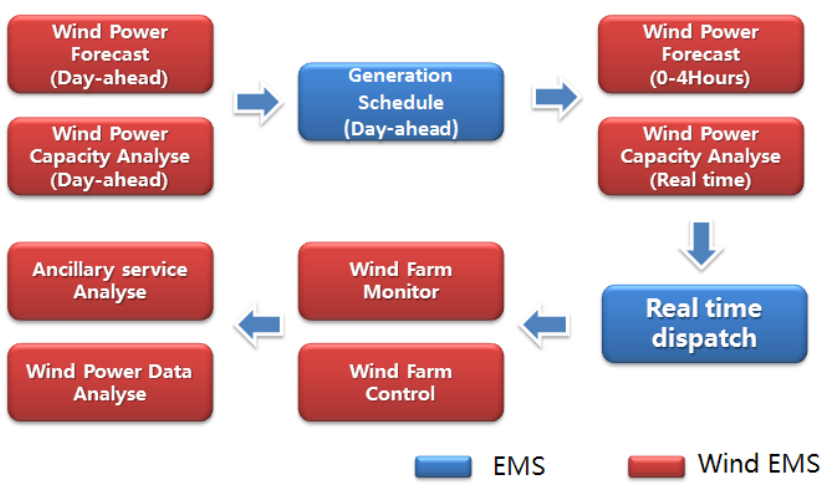

Fig.4 flow diagram of Wind Power Dispatching

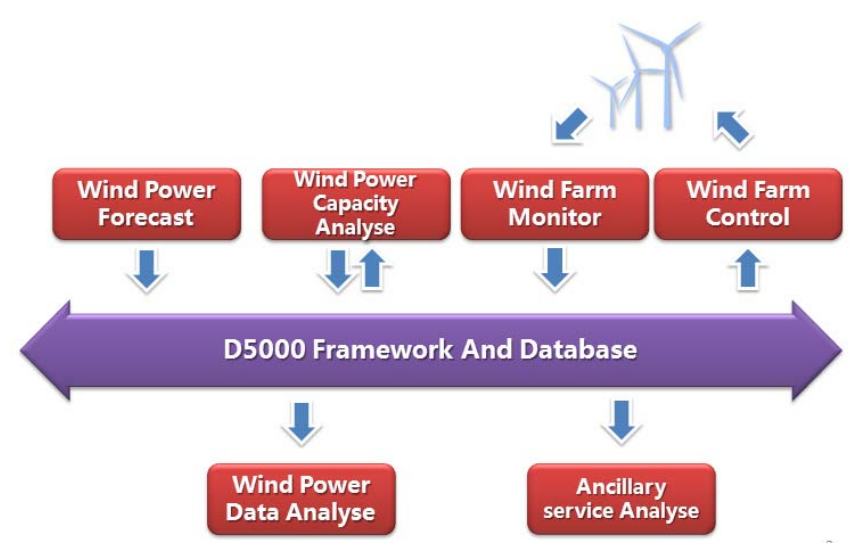

Fig.5 DFD of Wind EMS

Forecasting the output of wind power is one of the most effective and economic methods to increase peak regulation capacity. Based on wind power forecast, the dispatching department can arrange generation scheduling reasonably so as to reduce the system spinning reserve capacity. By forecasting output fluctuation of wind power, the power grid can also develop solutions to improve system security and economy ahead of schedule. Finally, it can improve the acceptance capacity of wind power and promote the development of renewable energy.

\subsection{Innovation of Inter-province Tie-Line Dispatching Mode}

The tie-lines among the provinces in NWGC takes the TBC fixed control mode, which does not suit the case that tie-line flow changes frequently after the integration of large-scale wind power. Furthermore, under the current power grid dispatching mode that province is entity and self-balancing, there is inter-province and inter-regional consumption barriers for wind power. As is known, isolated balance of each province is not conducive to fully digest of wind power. Tie-line control mode restricts the inter-province and interregional consumption of wind power. In this case, NWGC tends to redraw the existing control area and establishes a larger control area which can directly dispatch a number of hydropower, thermal power, and wind power. In this situation, large units can give full pay to the regulation performance and respond rapidly to the change of system status under complex operation mode. In this mode, the grid dispatching area is the first defense line of wind power regulation composed of large units dispatched by four subareas. The second defense line is the units dispatched by each subarea. There are two advantages in this way: Firstly, through wind power regulation in the whole grid the problem of system rapid control can be effectively solved; secondly, it meets the needs of classification management in large power grid and the responsibility division is clear.

\subsection{Improve Peak Regulation Ability of Power Grid Greatly}

The intermittent character of wind power exacerbates the contradiction between power generation and supply. The 
anti-peak regulation of wind power increases the load peakvalley, and thus the difficulty of power grid peak regulation is enhanced. In order to adapt to the integration of large-scale wind power, NWGC adopts many measures, including:

- conducting a survey of peak regulation capability of conventional power supply;

- running an experiment about deep peak regulation of thermal power units;

- investigating peak regulation capability of autonomous reserve power plants;

- $\quad$ speeding up implementation of proposed improvements;

- carrying out online information monitoring of heat supply units;

- maximizing peak regulation capacity of heat supply units;

- further improving optimal dispatching of cascade hydropower;

- fully excavating peak regulation capability of hydropower;

- optimizing conventional power startup mode;

- using dispatching automation system to realize dynamic monitoring of peak regulation capability;

- promoting peak-valley electricity pricing policy on generation

- $\quad$ giving conventional power units which take deep peak regulation in load valley preferential electricity price.

\subsection{Improve Spinning Reserve Management of Power Grid}

As mentioned by Eduardo M Gouveia and Manuel A.Matos (2004), when power grid is in normal operation, there must exist certain percent of spinning reserve capacity. If the spinning reserve of power grid is too large during load peak, it will further leads to the efficiency of regular power supply for reserve lower when wind power is big in power grid. If the spinning reserve of power grid is too small during load peak, we can not be able to ensure the safety of power frequency in the case of large fluctuation of wind power or the tripping of large units. Nowadays, the scheme of how to allocate the spinning reserve capacity depends on the constraint of tie-line check, and the tie-line scheduling model among diffenent provinces decides the scheme of how to allocate the spinning reserve capacity during load peak. So that they can meet the demands of spinning reserve in one province and prevent tie-line check, which will happen when there are forced electricity quantity in tie-line gateway in the condition of units tripping. In addition, static model is mostly adopted for reserve, therefore, there are not enough dynamic approaches to cope with load changes or wind power fluctuation. It can easily lead to too much spinning reserve during load peak, as well as shortage of spinning reserve capacity during load valley. When large-scale wind power is integrated, existing reserve provision can not be conducive to consume wind power at utmost. Considering operation characteristics of wind power and harmonization of regional power grid, NWGC refers to the adjustment of tie-line scheduling model among diffenent provinces, so that they can arrange the reserve capacity reasonably. According to super short-term wind power forecast, dynamic management should be strengthened, and the adjustability of power grid can also be improved in load valley.

\subsection{Improve Grid Transmission Capacity}

As mentioned above, in northwest China the wind power bases are far from load centers, and then there must exist strong grid structure to realize the long-distance transmission of wind power. Optimizing network structure and improving stable level are the most fundamental measures to greatly improve wind power transmission capacity. Firstly, Northwest Grid will install control devices like PSS to increase system damping. Secondly, through installing FACTS apparatuses, it can improve channel transmission capacity and the whole capacity of power grid by accelerating network reconstruction, accelerate breaking out of electromagnetic loop network and optimize network structure. Through testing large-scale power grid disturbance, the load model precision can be further advanced, the simulation calculation accuracy can be improved, analysis and calculation of power grid can also be improved, and thus the transmission capacity can be comprehensively developed. Moreover, NWGC should count and analyze the power supply structure, load characteristics and regulation performance of conventional units in areas with integration of large-scale wind power, rationally schedule tie-line planning and operation mode of local conventional units combining with day-ahead and short-term wind power forecast results, to avoid occupying additional power transmission channel and make full use of rank form while using transmission channel.

\subsection{Strengthen Wind Power Dispatching Control under Contingency}

According to operation experience at home and abroad, it has been proved that wind power may exacerbate accidents under contingency, beacuse some wind turbines do not have LVRT (Low Voltage ride through) ability, or frequency protection setting can not fully meet specified requirements. As a result, we should strengthen wind power dispatching under contingency to ensure system safe. NWGC has drawn up an accident case in advance for large-scale integration of wind power, and it also strengthens dispatchers' training and incidental drill, carrying out joint drill with wind farm rugularly. According to requipments of system voltage and frequency in emergency and restorationare condition, combined with influnce of wind power on voltage and frequency, wind power has been reasonably dispatched, and the scheme and ranking form of wind power's resection and restorationare are also established. In the case that there are too many wind dispatching objects, excellent organized scheme should be established with the help of dispatching automation system. 


\subsection{Orchestrate the Development of Wind Power and Power Grid}

According to the plan of developing wind power, we need to carry out special research on transmission plan in large-scale wind power base and areas with centralized integration of wind power, speed up the smart grid construction, and promote the construction of large-scale wind power base and transmission project, especially for the construction of DC delivery project in Jiuquan wind power base, to optimize wind power in large scale. In 2020, Jiuquan wind power base will reach $12,000 \mathrm{MW}$. Northwest Grid need to construct five circuits of $750 \mathrm{kV}$ transmission line in order to locally consume $8,000 \mathrm{MW}$ wind power. The excess $4,000 \mathrm{MW}$ wind, bounded with $5,000 \mathrm{MW}$ thermal power, will be transmitted from Jiuquan to Changsha in Hunan by one circuit of UHV DC transmission line.

\subsection{Strengthen the Research on Energy Storage and Load Side Guidance}

In future, NWGC will develop a series of research which contain rapid regulation power of inter-region and complementary characteristics and unified dispatching technology of large-scale wind power. Through developing research and application of large-scale energy storage technology, the intermittent and uncertain characters of wind power can be overcome, and substantially the acceptance capacity of wind power can also be increased. By researching load guidance and arrangement, optimizing peak-valley properties, and carrying out the controlled load research, a certain degree of manual intervention of load peak-valley can be achieved. By promoting peak-valley price, developing intelligent arrangement of demand side, relying on real-time price to realize rational allocation of electrical resources, and reducing peak-valley differences, the acceptance capacity of wind power can be increased.

\section{CONCLUSIONS}

Integration of large-scale wind power has great affection to power system. Through strengthening the $750 \mathrm{kV}$ network, increasing regional power export, developing Wind EMS, improving wind power prediction, jointly dispatching of wind power and other power plants, and introducing new power market mechanisms, the Northwest grid will effectively solve these problems, which promotes the steadily development of the Northwest grid of China.

\section{REFERENCES}

Bechrakis, D. A., Deane, J. P. and McKeogh, E. J. (2004). Wind resource assessment of an area using short term data correlated to a long term data set. Solar Energy, 76 (6):725-732.

Chen C.L.(2008). Optimal wind-thermal generating unit commitment. IEEE Transactions on Energy Conversion, 23 (1) :273-280.

Chompoo-Inwai, C., Lee,W.J. and Fuangfoo,P. et al (2005). System impact study for the interconnection of wind generation and utility system. IEEE Transactions on Industry Applications, 41 (1):163-168.

Dresden J and Belmans R. (2006). Distributed generation: challenges and possible solutions. 2006 IEEE Power Engineering Society General Meeting, Montrea Canada, June 18-22.

Eduardo M Gouveia, Manuel A.Matos (2004). Operational reserve of a power sysem with a large amount ofwind power. 8th International Conference on Probabilistic Methods Applied to Power Systems. September 12-16.

Ha, L.T. and Saha, T.K. (2004). Investigation of power loss and voltage stability limits for large wind farm connections to a subtransmission network. Power Engineering Society General Meeting 2004, 2:2251-2256.

Holttinen, H., Finland, VTT. and Pedersen, J. et al. (2003). The effect of large-scale wind power on a thermal system operation. Proceedings of the 4th International Workshop on Large-Scale Integration of Wind Power and Transmission Networks for Offshore Wind Farms.

Landberg, L., Giebel,G., Nielsen, H.A. et al. (2003). Shortterm prediction-An oerview. Wind Energy, 6 (3):pp. 273280.

Niknam, T., Ranjbar, A. M., Shirani, A. R. (2008). Impact of distributed generation on volt/var control in distribution networks. 2008 IEEE Power Tech on Science Direct, 49(12): 3417-3424.

Mendonca, A. and Lopes JAP. (2005). Impact of large scale wind power integration on small signal stability. International Conference on Future Power Systems. Amsterdam, Holland

Palsson, M.P. Toftevaag, T. Uhlen, K. (2002). Large-scale wind power integration and voltage stability limits in regional networks. Power Engineering Society Summer Meeting.

Slootweg, G. and Kling, W. L (2003). The impact of large scale wind power generation on power system oscillations. Electric Power Systems Research. 67(1):920.

Vladislav A (2003). Analysis of dynamic behavior of electric power systems with large amount of wind power. Copenhagen: Technical University of Denmark.

Wiik, J., Gjerde, J.O., Gjengedal, T., et al (2002). Steady state power system issues when planning large wind farms. IEEE Power Engineering Society Winter Meeting, $1: 366-371$. 